\title{
Crise Econômica Brasileira e Ajuste da Ocupação: Uma Análise para Diferentes Grupos de Trabalhadores entre 2012 e 2017
}

\author{
Davi Winder Catelan $^{1}$ | Marina Silva da Cunha ${ }^{2}$ (iD \\ ${ }^{1}$ Universidade Federal do Paraná. E-mail: daviwindercatelan.ecae@gmail.com \\ ${ }^{2}$ Universidade Estadual de Maringá. E-mail: mscunha@uem.br
}

\begin{abstract}
RESUMO
O objetivo deste artigo é verificar os efeitos imediatos da crise econômica brasileira sobre o nível de ocupação de diferentes grupos de trabalhadores para o Brasil e as unidades federativas e identificar os fatores explicativos das diferenças dos grupos no ajuste ocupacional. Para tanto, é aplicada a decomposição de Shapley, utilizando os microdados da PNADC para o período 2012-2017. Em função da crise econômica, os grupos de homens, menos escolarizados, adultos e não brancos sofreram as maiores perdas relativas de ocupação em relação aos grupos de mulheres, mais escolarizados, jovens e não brancos. As maiores reduções nas ocupações dos trabalhadores homens e adultos foram explicadas, sobretudo, pelos altos niveis de emprego pré-crise desses indivíduos e, no caso dos homens, por sua maior representatividade na indústria. Já os menos escolarizados e os não brancos foram, comparativamente, mais afetados devido à redução mais expressiva no nível de ocupação setorial desses trabalhadores.
\end{abstract}

\section{PALAVRAS-CHAVE}

Mercado de trabalho, Crise econômica brasileira, Decomposição de Shapley

Brazilian Economic Crisis and Occupation Adjustment: An Analysis for Different Groups of Workers between 2012 and 2017

\begin{abstract}
This paper aims to verify the immediate effects of the Brazilian economic crisis on the employment ratio of different groups of workers in Brazil and in the Brazilian federative units and to identify the explanatory factors of the differences of the groups in the occupational adjustment. For that, Shapley decomposition is applied, using PNADC microdata for the period 2012-2017. Due to the economic crisis, groups of less educated, non-whites, adult and men suffered the greatest relative losses of occupation when in comparison to groups of more educated, young, non-whites and women. The greatest reduction in the occupations of male and adult workers were explained, primarily due to their higher initial employment level and, in the case of men, by their greater representativeness in the industry. Less educated individuals and non-whites workers were more affected due to a significant reduction in the sectoral occupation level of these workers.
\end{abstract}

\section{KEYWORDS}

Labor market, Brazilian economic crisis, Shapley’s decomposition

\section{CLASSIFICAÇÃO JEL}

J21, E24, E32 


\section{Introdução}

A crise econômica brasileira, apesar de assumir proporções mais graves no biênio 2015-2016, teve como prelúdio uma combinação de choques externos e problemas macroeconômicos internos iniciados em anos anteriores. Esses choques externos isto é, a piora dos termos de troca e a elevação da taxa de câmbio brasileira - estiveram associados às mudanças das condições econômicas internacionais desde a crise financeira internacional de 2008. Já os problemas macroeconômicos domésticos ocorreram em meio ao aumento das incertezas em função, principalmente, da deterioração fiscal e da evolução da taxa de juros (Barbosa Filho, 2017).

Como decorrência do choque recessivo, os indicadores do mercado de trabalho passaram a apresentar resultados negativos, rompendo com o contínuo processo de melhoria das condições de trabalho que ocorria no país desde o início do século XXI (Pochmann, 2015; Souen, 2017). Particularmente, a contar de 2015, houve uma reversão do crescimento da taxa de ocupação e do rendimento do trabalho, além de um aumento da desocupação (Instituto Brasileiro de Geografia e Estatística - IBGE, 2018; Pochmann, 2018). Ademais, a indústria, comparada aos demais setores, sofreu os piores impactos da crise, denotando as reduções mais bruscas do emprego (Pochmann, 2018; Instituto Brasileiro de Geografia e Estatística - IBGE, 2018) e do PIB setorial (Cardoso e Jaenisch, 2017; Souen, 2017).

Os impactos das flutuações econômicas tendem a atingir os trabalhadores desproporcionalmente, afetando, em grande medida, a vulnerabilidade dos indivíduos menos favorecidos do mercado de trabalho (Cho, 2013). Isso sugere que a desigualdade social, resultante de componentes estruturais, agrava-se em consequência de fatores conjunturais, como crises econômicas. Na maioria dos países em desenvolvimento, o trabalho é o único ativo de grande parte da população, por isso, os mercados laborais desempenham um papel crucial na forma como os ciclos econômicos afetam o bem-estar social, a desigualdade e a pobreza.

Assim, o presente estudo busca responder às seguintes questões: dadas as características individuais dos trabalhadores, quais grupos de indivíduos se mostraram mais vulneráveis ao ciclo recessivo e, portanto, tiveram as maiores perdas de emprego? Ademais, quais fatores explicam as diferenças dos grupos no ajuste ocupacional?

O estudo justifica-se por, pelo menos, três motivos. Primeiro, a literatura que analisa os efeitos das recessões sobre o mercado de trabalho centra-se, especificamente, nas crises internacionais. É preciso ressaltar que, sem efeitos externos significativos, as crises econômicas nacionais são muito diferentes das crises internacionais (Cho, 2013). Desse modo, o estudo favorece o entendimento sobre as consequências das crises domésticas no mercado de trabalho.

Em segundo lugar, um exame das diferenças cíclicas de emprego entre os grupos é importante, porque uma perspectiva agregada não evidencia que os custos dos 
ciclos são assimetricamente transmitidos entre os trabalhadores. Essa assimetria tende a impactar o comportamento cíclico da desigualdade e, portanto, afeta os custos agregados dos ciclos econômicos (Bredemeier, 2017). De fato, na literatura, não há consenso quanto aos efeitos das crises econômicas para diferentes grupos, desse modo, o estudo busca contribuir com esse entendimento.

Por fim, nas nações em desenvolvimento, os mercados de trabalho são um canal fundamental através do qual as transformações macroeconômicas afetam o bem estar-social (Gutierrez, 2007). Assim, para os formuladores de políticas que buscam estabilizar o emprego ao longo do ciclo, é importante identificar os grupos, os setores econômicos e as regiões mais afetados pela recessão.

Nesse contexto, o objetivo central do artigo é verificar os efeitos imediatos da crise econômica brasileira sobre o nível de ocupação de diferentes grupos de trabalhadores para o Brasil e as unidades federativas (UFs), bem como identificar os fatores que explicam as diferenças dos grupos no ajuste ocupacional. Para tanto, o método aplicado é a decomposição de Shapley, utilizando os dados da Pesquisa Nacional por Amostra de Domicílios Contínua (PNADC) para o período 2012-2017.

O estudo está dividido em mais quatro seções, além desta introdução. Na seção 2, é apresentada a revisão de literatura sobre o tema. Na seção 3, descrevem-se a base de dados e a metodologia adotada. Na seção 4, são discutidos os resultados. A última seção contém as considerações finais.

\section{Evidências dos impactos das crises econômicas em dife- rentes tipos de trabalhadores}

Apesar de alguns estudos descreverem os efeitos das recessões econômicas em grupos específicos de trabalhadores, poucos se preocupam em distinguir os fatores que explicam as diferenças dos grupos nos ajustes de emprego. Conforme Cho (2013), há três mecanismos que explicam os diferentes níveis de vulnerabilidade entre os indivíduos diante dos choques recessivos: $(i)$ as diferenças setoriais dos trabalhadores; (ii) as decisões das firmas em relação à demanda de mão de obra; e (iii) o comportamento dos trabalhadores quanto à sua oferta de trabalho.

Com relação ao primeiro mecanismo, as diferenças no ajuste se devem, em parte, à segregação ocupacional e ao grau de exposição dos segmentos aos choques. Em muitos países, os homens são mais afetados do que as mulheres pelas flutuações econômicas, devido ao comportamento pró-cíclico de alguns setores econômicos tradicionalmente masculinos, como a construção civil. As mulheres, por sua vez, tendem a estar inseridas em setores menos expostos aos ciclos, como os serviços e a administração pública (Hoynes e Schaller, 2012; Bredemeier, 2017).

A literatura que trata da segmentação no mercado laboral abrange um amplo espectro de pontos de vista que compartilham a hipótese de que esses mercados são 
segmentados e de que os problemas de distribuição de renda, desemprego e discriminação são resultados dessa segmentação (Taubman e Wachter, 1986). A ideia central é que o mercado de trabalho é composto por dois mercados distintos: o mercado primário e o secundário. O primeiro mercado é constituído por firmas intensivas em capital, com processos produtivos em larga escala, alta produtividade e relativo amparo trabalhista; enquanto o mercado secundário é caracterizado por firmas intensivas em trabalho, estagnação tecnológica, pouca produtividade e reduzida proteção social. Essa segregação, associada ou agravada pelas disparidades nos atributos produtivos dos trabalhadores e pela discriminação, faz com que algumas minorias sejam alocadas em mercados secundários, originando a segmentação por cor, por sexo, por idade, etc. (Reich e Edwards, 1973).

Para autores como Doeringer (1985), a segmentação é consequência de níveis diferenciados de capital humano entre os indivíduos e de suas características pessoais. Outros autores, no entanto, defendem que a segmentação se deve às características intrínsecas às firmas, como os diferentes níveis tecnológicos e as particularidades de emprego (Bluestone, 1968; Vietorisz, 1973). Um outro ponto de vista argumenta que a segmentação é resultado de um processo histórico e da existência de diferentes classes sociais, o que favorece uma relativa imobilidade ocupacional (Reich e Edwards, 1973).

O segundo mecanismo que explica os diferentes niveis de vulnerabilidade entre os indivíduos se refere à decisão das firmas quanto aos tipos de trabalhadores a serem contratados ou demitidos em meio a um ambiente recessivo. Tal decisão relaciona-se à percepção das empresas quanto à produtividade dos trabalhadores e a seu apego ao mercado de trabalho. A teoria indica que o mercado de trabalho opera de maneira imperfeita devido, entre outros motivos, à escassez de informações em relação aos trabalhadores e aos estereótipos estatísticos. Nesse sentido, os indivíduos negros, as mulheres e os jovens, por exemplo, acabam sendo negativamente afetados, pois são, comumente, associados à falta de experiência, à maior rotatividade e à baixa produtividade, o que os torna mais suscetiveis ao desemprego (Arrow, 1971; Phelps, 1972).

Ademais, a existência de discriminação no mercado laboral faz com que alguns grupos sejam valorados, não apenas por suas características produtivas, mas também por suas características não produtivas, como a raça e o sexo (Arrow, 1971). Essa discriminação, muitas vezes, é resultante da assimetria de informações existente, o que permite que alguns indivíduos sejam valorados de acordo com as características médias do grupo a que pertencem, ao invés de serem levadas em consideração suas características individuais de produtividade (Phelps, 1972).

Quanto ao último mecanismo, as diferenças também se devem às decisões individuais dos trabalhadores sobre sua oferta de trabalho. A teoria econômica sugere dois efeitos relacionados a tal decisão diante da queda do nível de renda familiar: o efeito trabalhador adicional e o efeito desalento. No primeiro deles, quando um chefe de 
família perde seu emprego, um membro secundário busca se inserir na força de trabalho, como meio de manter a renda doméstica. Mas, se prevalece o efeito desalento, os trabalhadores optam por deixar o mercado de trabalho por estarem desencorajados a buscarem emprego durante a recessão (Gonzaga, 2011).

Com relação à literatura que analisa empiricamente a vulnerabilidade dos trabalhadores frente às crises econômicas, alguns estudos mostram que, em muitos países em desenvolvimento, a mão de obra feminina está inserida, sobretudo, nos setores exportadores de baixa e média intensidade tecnológicas, como a indústria têxtil (Bangladesh, Camboja, Nicarágua, Filipinas e Tunísia) e a agricultura de alto valor (Equador, Tailândia e Uganda). Assim, no que concerne às crises econômicas da década de 1990 e de 2008, a exposição mais acentuada desses setores aos choques recessivos resultou em maiores perdas salariais e de emprego para as mulheres, conforme os estudos de Sabarwal e Buvinic (2012), Signorelli e Marelli (2012) e Haouas e Guirreri (2014).

Resultados díspares são encontrados para os países desenvolvidos, onde os homens são mais propensos do que as mulheres a trabalharem em segmentos altamente pró-cíclicos, como o setor industrial e o financeiro, incluindo a construção civil e os setores exportadores. As mulheres, por outro lado, tendem a estar empregadas nos serviços e na administração pública (Hoynes e Schaller, 2012; Bredemeier, 2017). Em função disso, na crise financeira internacional de 2008, os homens sofreram os piores efeitos, conforme os trabalhos de Verick (2009) para os países da OCDE, de Barakat (2010) para os países europeus e de Elsby e Sahin (2010), Hoynes e Schaller (2012) e Bredemeier (2017) para os Estados Unidos.

Além disso, alguns trabalhos sugerem que o comportamento da oferta de mão de obra feminina durante as crises das décadas de 1980 e 1990, também, diferiu entre as nações desenvolvidas e em desenvolvimento. Em países de baixa e média renda, como o México e a Indonésia, prevaleceu o efeito trabalhador adicional para as mulheres (Smith, 2002; Parker, 2004), enquanto, nos países de alta renda, prevaleceu o efeito desalento (Sabarwal e Buvinic, 2012). Para o Brasil, Gonzaga (2011) verificam fortes evidências da existência do efeito trabalhador adicional para as mulheres diante da perda de emprego dos maridos entre 1991/2002. Já Silva (2018) observa o efeito do trabalhador adicional das cônjuges, frente à perda de trabalho dos maridos no Brasil entre 2012 e 2017.

Com relação às diferenças de idade, estudos passaram a analisar, especificamente, os efeitos dos choques recessivos sobre os trabalhadores mais jovens, pois, na maioria dos países, a taxa de desemprego juvenil é superior à taxa dos adultos (Quintini e Martin, 2007; Choudhry e Signorelli, 2012). Fato verificado também no Brasil (Flori, 2005; Instituto Brasileiro de Geografia e Estatística - IBGE, 2018).

Em contraste com os estudos sobre a vulnerabilidade por sexo, a elevação da vulnerabilidade juvenil, em função das crises econômicas, é confirmada em países de 
diferentes niveis de renda. Particularmente, considerando as crises financeiras da década de 1990 e a crise internacional de 2008, houve substancial aumento do desemprego juvenil nos países europeus e nos EUA, segundo Verick (2009), Elsby e Sahin (2010), Barakat (2010), Choudhry e Signorelli (2012) e Hoynes e Schaller (2012). O mesmo foi verificado para países de renda média (Choudhry e Signorelli, 2012; Cho, 2013; Vukšic, 2014).

Os impactos diferenciados entre os jovens e os demais podem estar relacionados ao baixo capital humano desses indivíduos e à maior rotatividade no emprego, o que repercute na segregação ocupacional e nas decisões de demanda por trabalho das firmas (Cho, 2013). Nos países de renda média, é comum, em meio a uma recessão, os jovens deixarem de se qualificar para ingressarem prematuramente no mercado de trabalho (Fallon, 2002). Para o Brasil, Oliveira e Oliveira (2014) averigua que a transição de homens chefes de família para o desemprego aumenta a probabilidade de o filho entrar no mercado de trabalho, indicando a existência de um efeito trabalhador adicional positivo para os jovens. Nos países desenvolvidos, de maneira oposta, os jovens tendem a aumentar a demanda por educação para evitar o mercado de trabalho em crise (Barakat, 2010). Ainda, esses trabalhadores, assim como os homens, costumam ser mais representativos nos setores pró-cíclicos, como a construção civil (Hoynes e Schaller, 2012; Bredemeier, 2017).

Quanto à vulnerabilidade da mão de obra pouco qualificada, as conclusões são consensuais para as nações desenvolvidas, indicando uma maior vulnerabilidade desses indivíduos, devido, entre outras razões, à sua maior representatividade nos setores pró-cíclicos. No caso dos países europeus e dos EUA, as crises financeiras da década de 1990 e de 2008 afetaram, sobretudo, os indivíduos menos qualificados (Elsby e Sahin, 2010; Barakat, 2010; Hoynes e Schaller, 2012). Já para os países de médio desenvolvimento, os resultados não são claros. Alguns estudos mostram que, como consequência da crise de 2008, a educação adicional reduziu a perda do emprego na Croácia (Vukšic, 2014) e no Peru (Glewwe, 1998). Cho (2013), por outro lado, mostram que, para o caso de dezessete países de renda média, os efeitos dessa mesma crise foram mais graves para os mais qualificados.

No que diz respeito ao Brasil, Pochmann (2015) utiliza os dados da Pesquisa Mensal do Emprego (PME) e aponta que nos sete primeiros meses de 2015 as taxas de ocupação das mulheres e de indivíduos menos escolarizados caíram mais do que as dos homens e dos mais escolarizados. Já os jovens tiveram menores perdas de emprego do que os adultos. Furtado (2016), valendo-se dos dados da Pesquisa Nacional por Amostra de Domicílios (PNAD), ressalta que os jovens se mostraram mais vulneráveis à crise econômica em comparação às faixas superiores de idade, apresentando as elevações mais expressivas da desocupação entre os primeiros trimestres de 2012 e 2016. Proni (2015), por sua vez, toma como base os microdados da PNAD e atesta que, no ano de 2015, a elevação do desemprego foi mais expressiva para as mulheres e para os negros, em comparação aos homens e brancos. Mais recentemente, Poch- 
mann (2018) utiliza os dados da PNADC e aponta que, entre o segundo trimestre de 2014 e o primeiro de 2018, as taxas de ocupação das mulheres e dos trabalhadores nas faixas superiores de idade apresentaram uma recuperação, mas, os homens e os indivíduos mais jovens mantiveram taxas crescentes de desemprego.

As evidências discutidas sugerem que, além da segregação no mercado de trabalho, os demais mecanismos explicativos devem ser considerados para entender as diferenças dos grupos na resposta à crise econômica brasileira. Portanto, o presente estudo busca contribuir para essa literatura, já que não há um consenso quanto aos efeitos de uma crise econômica para diferentes grupos de trabalhadores.

\section{Metodologia}

\subsection{Base de dados}

No estudo, são utilizados os microdados da PNADC, considerando o período entre o primeiro trimestre de 2012 e o quarto trimestre de 2017, para o Brasil e as unidades federativas. A motivação para o período de estudo se refere ao fato de que, entre os anos 2012 e 2017, o nível de atividade econômica brasileira passou por oscilações significativas, repercutindo nos indicadores de trabalho. O PIB brasileiro apresentou expansão, desaceleração e estagnação entre 2012 e 2014, decrescimento entre 2015-2016 e pequena recuperação em 2017. Entre 2012 e 2014, houve incremento da ocupação, do emprego formal e redução da desocupação (Cacciamali, 2016; Instituto Brasileiro de Geografia e Estatística - IBGE, 2018). Nos três anos seguintes (2015-2017), houve deterioração nesses indicadores (Instituto Brasileiro de Geografia e Estatística - IBGE, 2018; Pochmann, 2018).

Os trabalhadores foram divididos em oito grupos: (i) homens, (ii) mulheres, (iii) trabalhadores com alta escolaridade, (iv) trabalhadores com baixa escolaridade, $(v)$ jovens, (vi) adultos, (vii) brancos e (viii) não brancos. Os jovens possuem de 14 a 24 anos e os adultos englobam os indivíduos com idade entre 25 e 64 anos. Quanto à escolaridade, há dois grupos: alta escolaridade (aqueles que possuem, no mínimo, o ensino médio completo) e baixa escolaridade (indivíduos que possuem, no máximo, o ensino médio incompleto). Os grupos de cor/raça são compostos por brancos (brancos) e não brancos (pretos e pardos).

Quanto aos indicadores utilizados, foram selecionados os níveis de ocupação e de desocupação, as taxas de participação e de não participação na força de trabalho, as taxas de ocupação e de desocupação, a participação dos trabalhadores ocupados nos setores formal e informal e a participação dos trabalhadores ocupados na agricultura, na indústria e nos serviços ${ }^{1}$. Portanto, os setores econômicos foram agrupados em

\footnotetext{
${ }^{1}$ Conceitualmente, os níveis de ocupação e de desocupação referem-se ao percentual da população em idade ativa (PIA) ocupada e desocupada. Já as taxas de participação e de não participação na força de trabalho aludem, respectivamente, ao percentual da PIA dentro e fora da força de trabalho. Por último, as taxas de ocupação e de desocupação representam o percentual da população economicamente ativa (PEA) que está ocupada (PO) e desocupada (PD).
} 
três grandes setores: agricultura, indústria e serviços.

No estudo, promoveu-se a adequação da amostra, visando respeitar o plano amostral que lhe deu origem, uma vez que os dados amostrais obtidos por meio da PNADC não podem ser tratados como observações independentes e identicamente distribuídas, isto é, como se tivessem sido gerados por amostras aleatórias simples com reposição. A explicação é que o desenho amostral da PNADC incorpora os aspectos que definem um plano amostral "complexo", composto por estratificação, conglomeração e probabilidade proporcional ao tamanho nos mecanismos de seleção de sua amostra ${ }^{2}$.

No estudo, busca-se observar o ajuste dos indicadores de emprego em função da crise econômica. Esse ajuste é calculado por meio da diferença entre as variações médias de cada indicador selecionado entre os períodos pré-crise econômica (2012-2014) e de crise (2015-2017). O mesmo cálculo foi feito para obter o ajuste médio do PIB das UFs. Para isso, foram utilizados os valores fornecidos pelo IPEADATA, reajustados aos preços de 2016 com base no Deflator Implícito do PIB acumulado. No período de realização desta pesquisa, os valores de 2017 não estavam disponíveis, por isso, para o cálculo do ajuste do PIB, considerou-se como período de crise os anos de 2015 e 2016.

\subsection{Decomposição de Shapley}

Para identificar os fatores que explicam as diferenças dos grupos no ajuste do nível de ocupação em função da crise econômica, é utilizado o método desenvolvido por Cho (2013), que se constitui em uma generalização da decomposição de Shapley proposta por Shorrocks (2013). A abordagem de Shapley decompõe o produto de vários fatores, tomando a média simples da contribuição dos fatores sobre todas as permutações, em que um fator é variado, enquanto os outros são mantidos constantes. No entanto, a decomposição nem sempre é simétrica, ou seja, a contribuição média de cada fator no indicador selecionado pode mudar marginalmente dependendo da ordem em que os fatores são variados.

A primeira decomposição é empregada para desagregar as variações no nível de ocupação dos grupos ( $N o c p$ ) em uma parcela explicada pelas mudanças na taxa de ocupação (Tocp) e em outra parcela referente às mudanças na taxa de participação na força de trabalho (Tpar). Assim, o declínio do nível de ocupação pode ser atribuído à redução da taxa de ocupação, à redução da participação dos trabalhadores na força de trabalho ou a ambas. Por simplicidade, as variáveis nivel de ocupação e taxa de participação são citadas no texto apenas como ocupação e participação.

Conceitualmente, o nível de ocupação é determinado por Nocp $_{t}=$ Tocpt $_{t}$ part $_{t}$. Portanto, o ajuste da ocupação pode ser decomposto como:

\footnotetext{
${ }^{2}$ Sobre amostras complexas ver Silva e Lila (2002).
} 


$$
\Delta N o c p_{t}=\underbrace{\Delta \operatorname{Tocp}_{t} \overline{\operatorname{Tpar}}}_{1}+\underbrace{\overline{\operatorname{Tocp} \Delta \text { Tpart }_{t}}}_{2}
$$

em que $\Delta X_{t}=X_{t+1}-X_{t}$ para todas as variáveis e $\overline{T o c p}$ e $\overline{T p a r}$ representam, respectivamente, os valores médios das taxas de ocupação e da participação entre os períodos $t$ e $t+1^{3}$. O primeiro termo do lado direito da equação (1) é a parcela da variação do nível de ocupação que é explicada pela variação na taxa de ocupação e o segundo termo é a parcela explicada pela variação na participação na força de trabalho. A decomposição é aplicada para cada um dos oito grupos de trabalhadores.

A segunda decomposição é aplicada para verificar os fatores que explicam as diferenças dos grupos no ajuste da ocupação. Para as diferenças de sexo, por exemplo, o resultado de interesse é $\left(\Delta N o c p_{h, p 2}-\Delta N o c p_{h, p 1}\right)-\left(\Delta N o c p_{m, p 2}-\Delta N o c p_{m, p 1}\right)$ cujo subscrito $h$ refere-se ao sexo masculino e $m$ ao feminino. Para a obtenção desse resultado, primeiramente, assume-se que o nível inicial de ocupação (pré-crise) e a distribuição setorial de emprego são diferentes para cada grupo.

Isto posto, a proporção da ocupação nos setores de atividade para os grupos é definida como $S_{i t}=$ Nocp ${ }_{i t} / N_{\text {ocp }}$ o subscrito i se refere a cada um dos setores, tal que $\sum_{i}^{n} S_{i t}=1$.

A relação entre o nível de ocupação setorial $\left(N o c p_{i t}\right)^{4}$ e a ocupação $\left(N o c p_{t}\right)$ é dada por:

$$
N_{o c p}{ }_{i t}=S_{i t} N_{o c p}
$$

As taxas de variação da ocupação $\left(r_{t}\right)$ e da ocupação setorial $\left(r_{i t}\right)$ são definidas como:

$$
\begin{aligned}
r_{t} & =\frac{N_{o c p_{t+1}}-N o c p_{t}}{N o c p_{t}} \\
r_{i t} & =\frac{N_{o c p_{i t+1}}-N o c p_{i t}}{N o c p_{i t}}
\end{aligned}
$$

Por fim, a taxa de variação da ocupação pode ser expressa como uma média ponderada das variações setoriais, com os pesos determinados pela parcela de ocupação

\footnotetext{
${ }^{3}$ O período $t$ alude ao período pré-crise (2012-2014) e $t+1$ ao de crise (2015-2017)

${ }^{4}$ A variável $N o p c_{i t}$ representa a parcela da PIA ocupada no setor $i$, no período $t$.
} 
de cada setor:

$$
r_{t}=\sum_{i}^{n} S_{i t} r_{i t}
$$

Desse modo, a variação da ocupação em cada período de tempo é definida como:

$$
\Delta N o c p_{t}=N_{o c p} t_{+1}-N o c p_{t}=N o c p_{t} r_{t}=N o c p_{t} \sum_{i}^{n} S_{i t} r_{i t}
$$

Cada termo contém os três fatores que se combinam para explicar as variações no nível de ocupação para cada grupo: nível inicial de ocupação $\left(N_{o c p}\right)$, distribuição setorial $\left(S_{i t}\right)$ e variação na ocupação setorial $\left(r_{i t}\right)$. Como existem três fatores cujo produto é a variação na ocupação, utiliza-se a decomposição de Shapley para verificar a contribuição média de cada fator na explicação das disparidades dos grupos. Dada a propriedade assimétrica do método, calcula-se a contribuição de cada um dos três componentes em seis permutações.

Na primeira permutação, expressa na equação (7), preliminarmente, varia-se o nível de ocupação inicial, mantendo-se os demais componentes constantes. No segundo passo dessa mesma permutação, a distribuição setorial é variada, enquanto os outros componentes não variam. Finalmente, no passo três, varia-se a variação da ocupação setorial.

Da equação (6), aplicando a decomposição às diferenças de sexo no emprego, deriva-se ${ }^{5}$ :

$$
\begin{aligned}
\Delta \text { Nocp }_{h}-\Delta \text { Nocp }_{m} & =\underbrace{\left(\operatorname{Nocp}_{h}-N o c p_{m}\right) \sum_{i}^{n} S_{i h} r_{i h}}_{1} \\
& +\underbrace{N o c p_{m} \sum_{i}^{n}\left(S_{i h}+S_{i m}\right) r_{i h}}_{2} \\
& +\underbrace{N o c p_{m} \sum_{i}^{n}\left(r_{i h}-r_{i m}\right) S_{i m}}_{3}
\end{aligned}
$$

Portanto, a diferença no ajuste da ocupação entre os grupos é dividida em três

\footnotetext{
${ }^{5}$ Por simplicidade, o subscrito $t$ foi omitido da equação (7).
} 
parcelas, conforme a equação (7). A primeira parcela diz respeito à diferença de sexo no nível inicial de ocupação e indica até que ponto as disparidades absolutas resultam de uma redução percentual igual na probabilidade de trabalho de cada grupo. A segunda parcela da diferença é explicada pela segregação ocupacional de homens e mulheres. O terceiro componente é a parcela explicada pela diferença de sexo nas variações do nível de ocupação setorial. Essa última parcela capta tanto as decisões das firmas em relação à demanda por mão de obra quanto as decisões dos trabalhadores referentes à oferta de trabalho.

Um pequeno valor atribuído à terceira parcela, por exemplo, indica que os setores reduzem proporcionalmente o emprego tanto para os homens quanto para as mulheres. No entanto, como os homens, geralmente, compõem uma parcela maior da força de trabalho, reduções proporcionais para os dois grupos levariam a uma redução absoluta maior nos níveis de ocupação masculino, o que seria captado pela primeira parcela.

A equação (7) é um dos seis caminhos que podem ser usados para expressar a decomposição. Como não há um critério de escolha do caminho a ser adotado, que é determinado pela ordem em que os fatores são variados, calcula-se a média em todos os seis, conformes estão listadas a seguir:

tamanho

$$
\begin{aligned}
& \Delta \text { Nocp }_{h}-\Delta \text { Nocp }_{m}=\operatorname{Nocp}_{h} \sum_{i}^{n} S_{i h} r_{i h}-N_{o c p} \sum_{i}^{n} S_{i m} r_{i m} \\
& =\left(N_{o c p_{h}}-N_{o c p_{m}}\right) \sum_{i}^{n} S_{i h} r_{i h}+N o c p_{m} \sum_{i}^{n}\left(S_{i h}-S_{i m}\right) r_{i h}+N o c p_{m} \sum_{i}^{n}\left(r_{i h}-r_{i m}\right) S_{i m} \\
& =\left(N_{o c p_{h}}-N_{o c p_{m}}\right) \sum_{i}^{n} S_{i h} r_{i h}+N o c p_{m} \sum_{i}^{n}\left(S_{i h}-S_{i m}\right) r_{i m}+N o c p_{m} \sum_{i}^{n}\left(r_{i h}-r_{i m}\right) S_{i h} \\
& =\left(N_{o c p_{h}}-N_{o c p_{m}}\right) \sum_{i}^{n} S_{i m} r_{i m}+N_{o c p} \sum_{i}^{n}\left(S_{i h}-S_{i m}\right) r_{i m}+N o c p_{h} \sum_{i}^{n}\left(r_{i h}-r_{i m}\right) S_{i h} \\
& =\left(N_{o c p_{h}}-N_{o c p_{m}}\right) \sum_{i}^{n} S_{i m} r_{i m}+\operatorname{Nocp}_{h} \sum_{i}^{n}\left(S_{i h}-S_{i m}\right) r_{i h}+N o c p_{h} \sum_{i}^{n}\left(r_{i h}-r_{i m}\right) S_{i m} \\
& =\left(N_{o c p_{h}}-N_{o c p_{m}}\right) \sum_{i}^{n} S_{i m} r_{i h}+N o c p_{h} \sum_{i}^{n}\left(S_{i h}-S_{i m}\right) r_{i h}+N o c p_{m} \sum_{i}^{n}\left(r_{i h}-r_{i m}\right) S_{i m} \\
& =\left(N_{o c p}-N_{o c p}\right) \sum_{i}^{n} S_{i h} r_{i m}+N_{o c p} \sum_{i}^{n}\left(S_{i h}-S_{i m}\right) r_{i m}+N o c p_{h} \sum_{i}^{n}\left(r_{i h}-r_{i m}\right) S_{i h}
\end{aligned}
$$

Para a obtenção dos resultados da decomposição, são apresentadas as médias de participação de cada um dos três componentes nas seis equações. A mesma decomposição é aplicada para examinar as diferenças de idade, escolaridade e cor nos ajustes da ocupação. 


\section{Resultados e discussões}

\subsection{Ajustamentos agregados do mercado de trabalho brasileiro}

A crise econômica brasileira da década de 2010 tem afetado o bem-estar da sociedade, notadamente, através do mercado de trabalho. Nesse contexto, essa seção apresenta alguns indicadores referentes à extensão do choque e à natureza do ajuste do mercado laboral, para o Brasil e as unidades federativas. Para isso, os gráficos mostram a magnitude do ajuste dos indicadores de emprego no eixo vertical, em relação ao ajuste do PIB no eixo horizontal ${ }^{6}$. Os resultados se referem à diferença das variações médias de cada indicador entre os períodos pré-crise e de crise.

A Figura 1 ilustra as mudanças relativas à PIA, dividindo os trabalhadores entre ocupados, desocupados e inativos ${ }^{7}$. Já as Figuras 2 e 3 exibem os ajustes sobre a PEA, classificando os trabalhadores ocupados entre os setores de atividade e entre os setores formal e informal, respectivamente ${ }^{8}$. Verifica-se que, em média, a queda no nivel de ocupação teve como contrapartida a elevação no nivel de desocupação e o declínio na taxa de não participação. Isso sugere que a participação dos trabalhadores na força de trabalho foi contracíclica, corroborando os achados de Pochmann (2015) e de Souen (2017). Como indicam as linhas tracejadas (ajustes médios) na Figura 1, o ajuste médio da ocupação no Brasil foi de -1,16 p.p., enquanto os ajustes da desocupação e da não participação foram de 1,60 p.p. e -0,43 p.p., respectivamente.

A amplitude em que a ocupação declinou no período variou consideravelmente entre as UFs e isso se deve, parcialmente, aos diferentes comportamentos dos trabalhadores em relação à oferta de trabalho. Os resultados sugerem que em algumas UFs, como Roraima, Piauí e Alagoas, muitos trabalhadores optaram por deixar o mercado de trabalho em meio a deterioração econômica, elevando a não participação e, por isso, ocorreram maiores reduções do nível de ocupação.

Evidências díspares foram encontradas para as UFs das regiões Sul e Sudeste, onde aparentemente prevaleceu o efeito trabalhador adicional. Nesses locais, apesar de ocorrer um aumento na desocupação, essa foi, parcialmente, compensada por um aumento na participação dos trabalhadores no mercado laboral, o que favoreceu uma redução menor no nível de ocupação, como em São Paulo e no Espírito Santo, ou mesmo um aumento nesse indicador, como em Santa Catarina.

\footnotetext{
${ }^{6}$ As abreviaturas representam as UFs brasileiras: AC (Acre), AL (Alagoas), AP (Amapá), AM (Amazonas), BA (Bahia), CE (Ceará), DF (Distrito Federal), ES (Espírito Santo), GO (Goiás), MA (Maranhão), MT (Mato Grosso), MS (Mato Grosso do Sul), MG (Minas Gerais), PA (Pará), PB (Paraíba), PR (Paraná), PE (Pernambuco), PI (Piauí), RJ (Rio de Janeiro), RN (Rio Grande do Norte), RS (Rio Grande do Sul), RO (Rondônia), RR (Roraima), SC (Santa Catarina), SP (São Paulo), SE (Sergipe) e TO (Tocantins).

${ }^{7}$ Conceitualmente, a PIA pode ser dividida entre trabalhadores ocupados (PO), desocupados (PD) e não economicamente ativos (PNEA), portanto o somatório da variação dos três indicadores é zero, pois os trabalhadores que saem da ocupação só têm duas alternativas: permanecer na desocupação, buscando emprego, ou deixar a força de trabalho.

${ }^{8} \mathrm{Na}$ Figura 2, a PEA está dividida entre a PD e os trabalhadores ocupados inseridos nos três setores de atividade: agricultura, comércio e serviços. Já a Figura 3 segmenta a PEA entre a PD e a mão de obra ocupada formal e informal.
} 
Figura 1. Ajustes do emprego em relação à PIA, Brasil e unidades federativas, 2012-2017

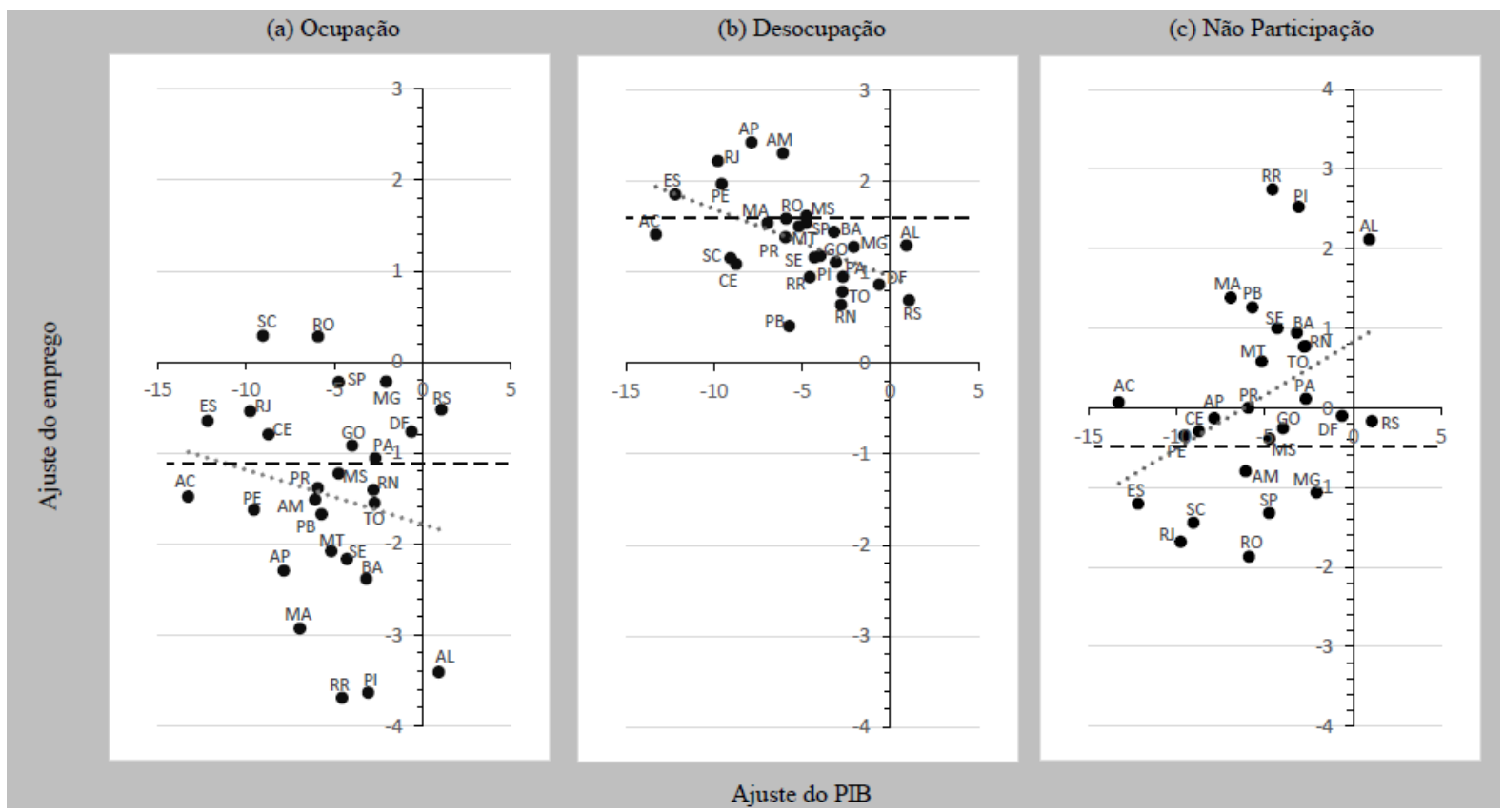

Fonte: Elaboração dos autores, a partir da PNADC/IBGE.

Nota: (a) Os valores plotados referem-se à diferença entre as variações médias dos períodos pré-crise e de crise para as variáveis de emprego (eixo vertical) e para o PIB das unidades federativas (eixo horizontal). (b) As linhas tracejadas representam os ajustes médios e as linhas pontilhadas as tendências.

O aumento na desocupação, por sua vez, esteve associado à queda no PIB em grande parte das UFs, como indica a linha de tendência negativamente inclinada na parte (b) da Figura 1. Entretanto, em algumas UFs, como Alagoas, Amazonas e Amapá, ocorreram maiores perdas de emprego do que seria de se esperar com base na queda do PIB.

Com relação à PEA, na Figura 2, nota-se que a indústria, em comparação aos demais setores, apresentou a maior redução no emprego, seguida pelo setor de serviços. A agricultura, por outro lado, denotou uma estabilidade na variação ocupacional. Especificamente, o ajuste médio da ocupação industrial foi de -1,16 p.p., enquanto nos serviços e na agricultura os ajustes foram de -1,15 p.p. e 0,02 p.p. Em algumas UFs, tais como a Paraíba, o Tocantins e o Rio Grande do Sul, o emprego agrícola apresentou maiores taxas de crescimento, o que atenuou a redução geral na ocupação.

Com efeito, em algumas UFs, a variação no emprego agrícola se correlacionou negativamente à variação no PIB, como se verifica pela linha de tendência no Gráfico (b) da Figura 2. O comportamento distinto da ocupação na agricultura está associado à natureza de seus postos de trabalho, em que prevalecem menor formalização e jornadas mais flexíveis de trabalho e também devido ao crescimento na produção agrícola, mesmo entre 2015 e 2016, ao contrário dos serviços e da indústria que apresentaram um declínio na atividade (Cardoso e Jaenisch, 2017). 
Figura 2. Ajustes do emprego em relação à PEA: taxa de desocupação e setores de atividade, Brasil e unidades federativas, 2012-2017

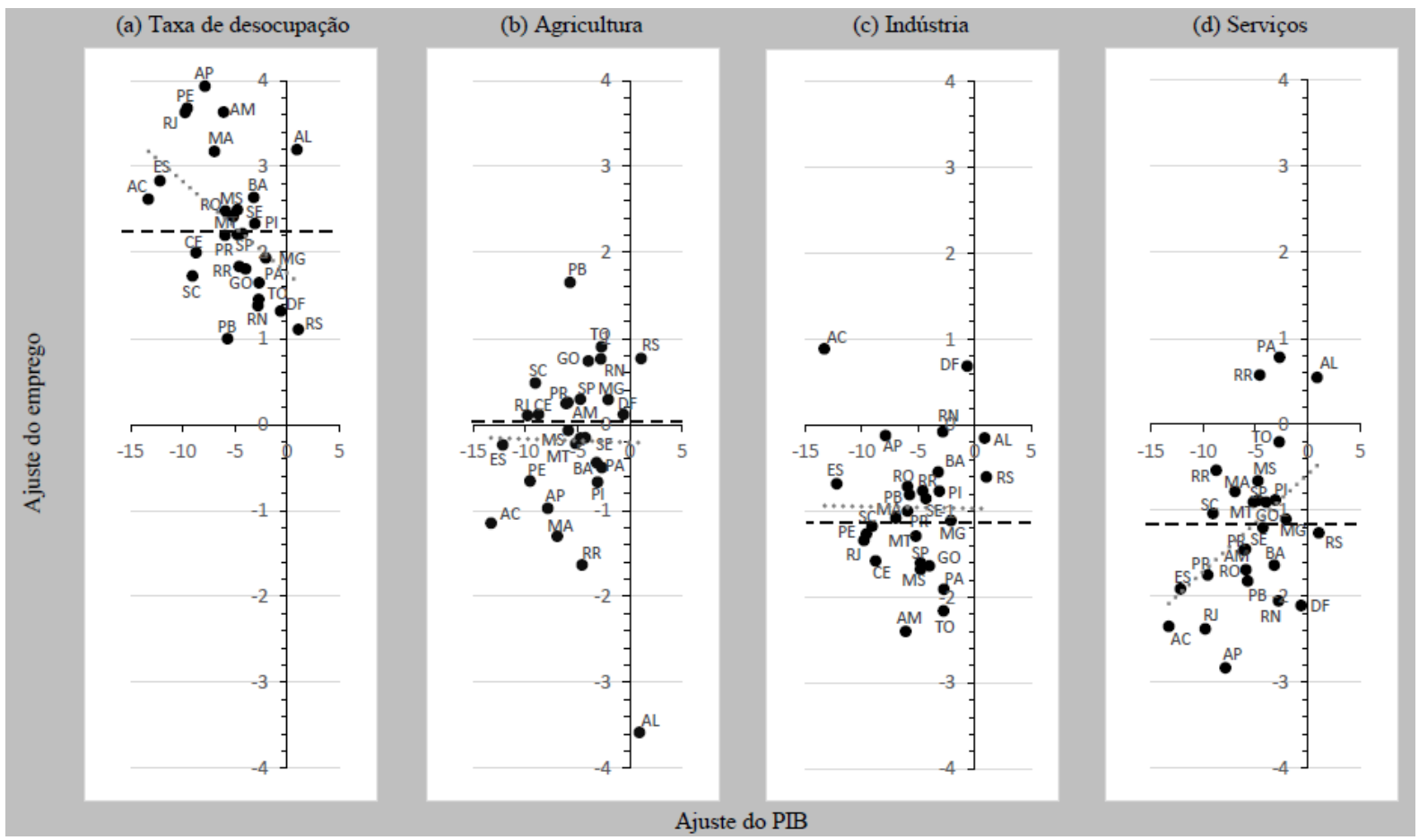

Fonte: Elaboração dos autores, a partir da PNADC/IBGE.

Nota: (a) Os valores plotados referem-se à diferença entre as variações médias dos períodos pré-crise e de crise para as variáveis de emprego (eixo vertical) e para o PIB das unidades federativas (eixo horizontal). (b) As linhas tracejadas representam os ajustes médios e as linhas pontilhadas as tendências.

O movimento anticíclico da agricultura brasileira pode ser explicado por alguns fatores. Primeiramente, os preços domésticos dos produtos agrícolas de exportação são mais afetados pelo desempenho dos preços internacionais das commodities e pelo câmbio do que pelas flutuações cíclicas nacionais. Ademais, os preços domésticos dos insumos agrícolas e os custos de transporte são influenciados pelo preço internacional do petróleo e, portanto, podem variar de forma autônoma ao ciclo econômico nacional. Finalmente, a agricultura, ao ser mais exposta aos choques externos, tem sua rentabilidade atrelada a variações exógenas ao ciclo econômico interno (Rezende, 1989).

Conforme a Figura 3, o declínio no emprego formal não resultou em um aumento equivalente no emprego informal, como pode ser verificado pelas diferentes magnitudes nos ajustes médios dos empregos formal e informal (linhas tracejadas). O ajuste médio do emprego formal no Brasil foi de -2,64 p.p., enquanto o ajuste do emprego informal foi de 0,36 p.p. No entanto, no Rio Grande do Sul, no Rio de Janeiro e em São Paulo, por exemplo, o emprego informal teve um aumento mais expressivo, sugerindo que o segmento informal teve um importante papel na absorção dos trabalhadores demitidos do setor formal.

No Brasil, alguns autores verificam que a realocação de trabalhadores do emprego 
para o desemprego ou para a informalidade é fruto do ciclo de negócios, de modo que a participação do setor informal no emprego total decresce durante os períodos de expansão e cresce durante as recessões (Neri, 2002). Assim, os resultados indicam que o setor informal, semelhantemente à agricultura, está menos sujeito à dinâmica econômica interna.

Figura 3. Ajustes do emprego em relação à PEA: taxa de desocupação e formalidade, Brasil e unidades federativas, 2012-2017

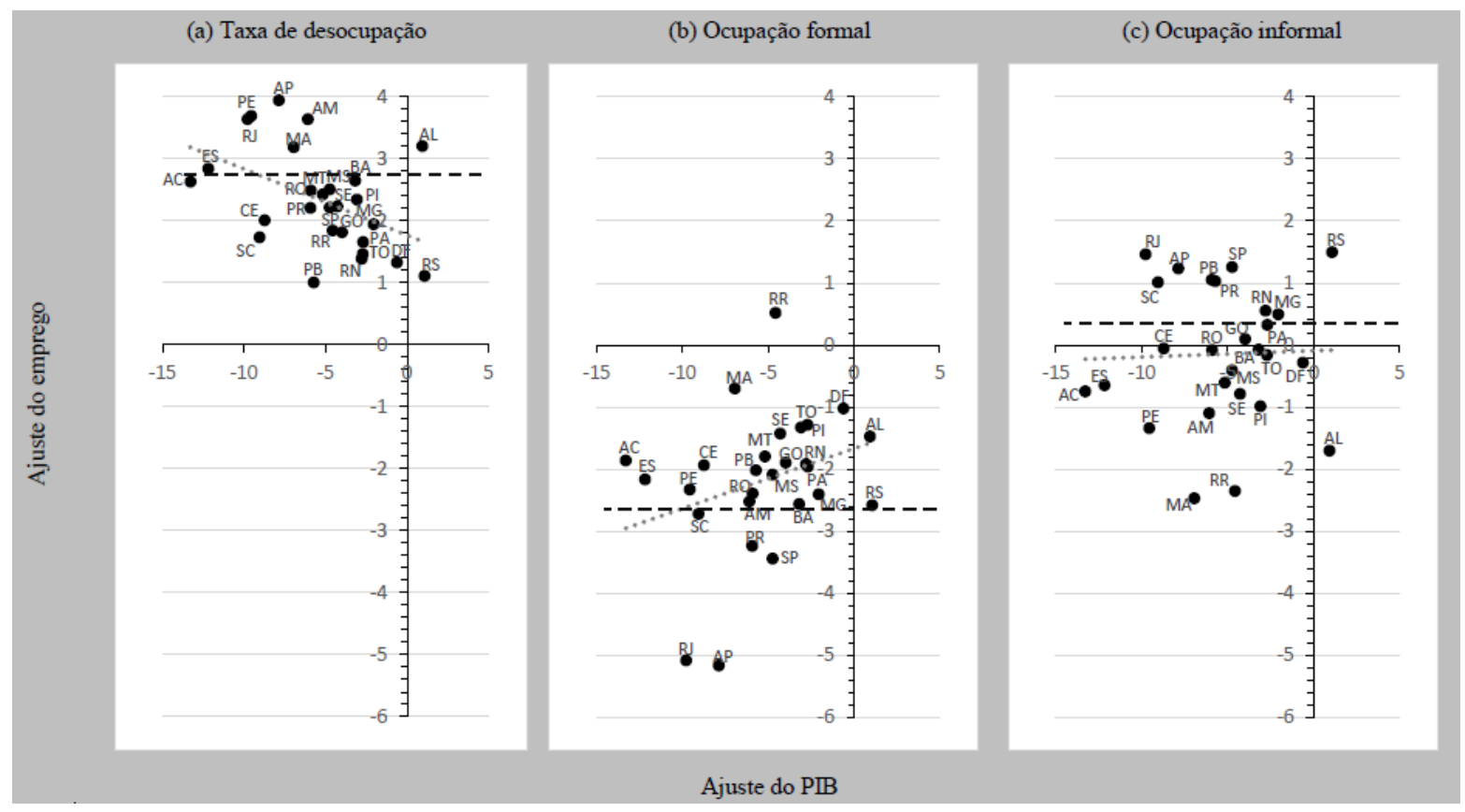

Fonte: Elaboração dos autores, a partir da PNADC/IBGE.

Nota: (a) Os valores plotados referem-se à diferença entre as variações médias dos períodos pré-crise e de crise para as variáveis de emprego (eixo vertical) e para o PIB das unidades federativas (eixo horizontal). (b) As linhas tracejadas representam os ajustes médios e as linhas pontilhadas as tendências.

Por conseguinte, as evidências discutidas indicam que o setor da agricultura e o emprego informal, caracterizados por empregos de menor qualificação, por salários inferiores e por um comportamento menos sujeito ao ciclo econômico, amorteceram a queda no emprego em algumas localidades, especialmente nas UFs mais desenvolvidas economicamente, contudo não foram suficientes para amenizar a elevação no desemprego no Brasil em geral.

\subsection{Ajustes do mercado de trabalho para diferentes grupos de trabalha- dores}

Esta seção aborda as duas decomposições destinadas a esclarecer como o ajuste do nível de ocupação diferiu entre os grupos de trabalhadores. O primeiro passo decompõe o ajuste ocupacional em uma parcela explicada pela variação na taxa de ocupação e em outra parcela explicada pela variação na participação no mercado de 
trabalho.

Primeiramente, na Tabela 1, observa-se que, para todos os grupos, a queda no nível de ocupação ocorreu em função do declínio na taxa de ocupação, enquanto a participação aumentou no período, reforçando as tendências apresentadas na Figura 1. Particularmente, as mulheres, os brancos e os jovens despontam como os grupos com os maiores aumentos na participação, corroborando as hipóteses de existência do efeito trabalhador adicional para as mulheres (Gonzaga, 2011; Silva, 2018) e para os jovens brasileiros (Oliveira e Oliveira, 2014).

Como se nota, o nível de ocupação médio dos homens (H) foi reduzido em 1,49 p.p. entre os períodos pré-crise e de crise, dos quais 1,58 p.p. (106,33\%) foi devido à queda na taxa de ocupação. Já a participação masculina no mercado de trabalho aumentou em 0,09 p.p. Para os individuos menos escolarizados (BE), o ajuste ocupacional foi de -1,30 p.p., devido à queda de -1,66 p.p. na taxa de ocupação e à elevação de 0,36 p.p. na participação. Quanto aos jovens (J), a redução de -0,76 p.p. no emprego só não foi maior porque a redução na taxa de ocupação $(-2,22$ p.p.) foi, parcialmente, compensada pela elevação na participação desses trabalhadores (1,46 p.p.). Os bran$\cos (\mathrm{B})$, por sua vez, apresentaram a diminuição menos expressiva no emprego entre os grupos (-0,53 p.p.), em função da queda de 1,24 p.p. na taxa de ocupação e do aumento de 0,71 p.p. na participação.

No que tange, especificamente, ao período de crise, nota-se que, com exceção dos homens, os demais grupos elevaram sua participação no mercado de trabalho, o que sugere novamente um comportamento anticíclico na oferta de trabalho. Contudo, a taxa de ocupação oscilou negativamente para todos os grupos entre 2015 e 2017, confirmando uma redução geral na demanda por mão de obra. Em suma, os recuos na taxa de ocupação foram menores para as mulheres, os mais escolarizados, os adultos e os brancos, quando comparados às demais categorias.

Nesse caso, o crescimento do emprego informal pode ter arrefecido a queda na taxa de ocupação para alguns grupos. Em especial, a mão de obra feminina, os mais qualificados, os adultos e os não brancos apresentaram, respectivamente, crescimentos de 3,30 p.p., 18,79 p.p., 2,91 p.p. e 2,38 p.p. no número de trabalhadores informais entre o primeiro trimestre de 2015 e o último trimestre de 2017. Já os homens, os menos escolarizados, os jovens e os brancos tiveram um desempenho pior, denotando variações de 1,01 p.p., -0,26 p.p., -2,35 p.p. e 1,38 p.p. no número de informais. 


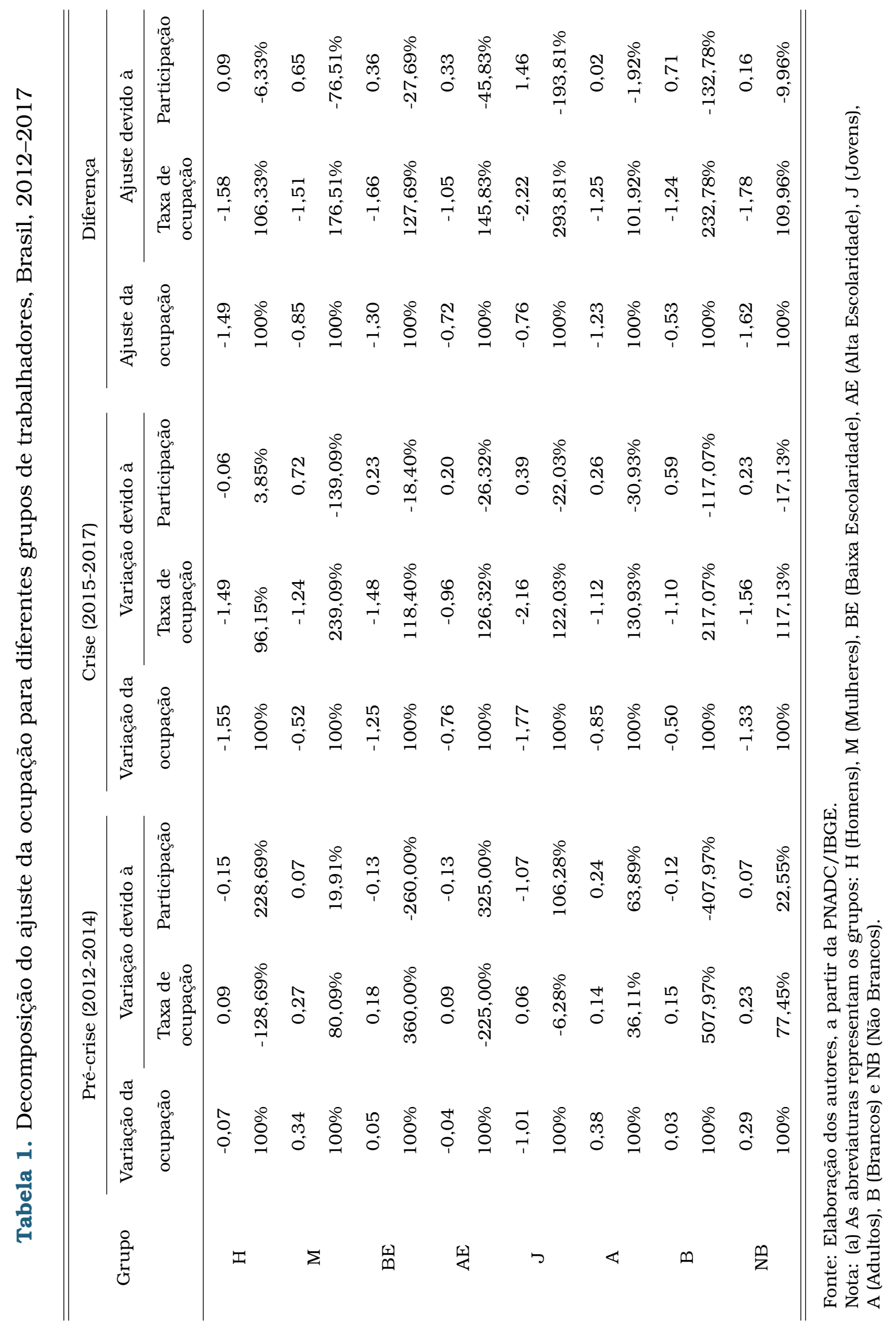


Nunes e Komatsu (2016) argumentam que, em um contexto de recessão, é possível haver um aumento no nível de empregos precários que possuem efeito anticíclico sobre a taxa de desemprego geral da economia. A justificativa, segundo os autores, é que a redução na probabilidade de admissão no emprego pode ser mais do que compensada pela redução na probabilidade de desligamento no segmento informal ${ }^{9}$.

Ainda, pode-se supor que os recuos menos expressivos nas taxas de ocupação das mulheres, dos indivíduos mais qualificados, dos adultos e dos brancos estão associados ao maior grau de formalidade desses trabalhadores no mercado laboral, de modo que a posse de carteira assinada contribui para a preservação de parte das ocupações durante o ciclo recessivo ${ }^{10}$.

Quanto aos fatores explicativos das diferenças dos grupos no ajuste do nível de ocupação, as Tabelas 2 e 3 decompõem as diferenças de sexo, escolaridade, idade e cor em três parcelas: diferença no nível inicial de ocupação, diferença na distribuição setorial e diferença na variação da ocupação setorial, para o Brasil e as UFs. Previamente, na parte (a) da Tabela 2 são apresentados os resultados para as diferenças de sexo, tendo como base de comparação os homens, em relação às mulheres.

Como indicado na Tabela 1, houve entre os dois períodos um ajuste de -1,49 p.p. na ocupação masculina e de $-0,85$ p.p. na ocupação feminina. Portanto, o valor de -0,63 ilustrado na parte (a) da Tabela 2 se refere à diferença de sexo no ajuste da ocupação, sinalizando que o nível de ocupação masculino caiu 0,63 p.p. a mais do que o feminino. A decomposição revela que a diferença de sexo no ajuste de emprego é explicada, mormente, pelos altos niveis de emprego pré-crise dos homens $(-0,46)$, representando $73,02 \%$ da diferença de sexo.

A distribuição setorial dos homens também levou a perdas expressivas de emprego para esses trabalhadores $(-0,41)$, correspondendo a $65,08 \%$ da diferença total, possivelmente, em razão de sua maior representatividade na indústria. Guanto à diferença nas variações da ocupação setorial, os homens retrataram um desempenho relativamente favorável, por isso, o valor de 0,24 é positivo para esse grupo. Tal resultado indica que os três setores reduziram o emprego para as mulheres em 0,24 p.p. a mais do que para os homens. Para entender a definição dessa parcela, deve-se considerar que o nível de ocupação setorial pode aumentar em função do crescimento na participação no mercado de trabalho ou por um aumento na taxa de ocupação setorial. Conforme a Tabela 1, todos os grupos apresentaram elevações na participação e recuos na taxa de ocupação, portanto, quando uma categoria de indivíduos denota um resultado comparativamente pior (negativo) nessa parcela, significa, grosso modo, que a redução na taxa de ocupação setorial foi maior para esse grupo.

\footnotetext{
${ }^{9}$ Isso explicaria a existência de uma correlação negativa entre a probabilidade de desligamento e o desemprego no Brasil entre o final de 2002 e início de 2003 (Nunes e Komatsu, 2016).

${ }^{10}$ No primeiro trimestre de 2015 , as mulheres, os mais escolarizados, os adultos e os brancos detinham, respectivamente, $57,43 \%, 75,29 \%, 57,46 \%$ e $62,55 \%$ dos seus trabalhadores em vagas formais de emprego, enquanto os homens, os menos qualificados, os jovens e os não brancos detinham, respectivamente, 55,97\%, 51,90\%, 52,17\% e 51,35\%.
} 
Tabela 2. Decomposição das diferenças no ajuste da ocupação por sexo e escolaridade, Brasil e unidades federativas, 2012-2017

\begin{tabular}{|c|c|c|c|c|c|c|c|c|}
\hline \multirow{3}{*}{$\mathrm{UF}$} & \multicolumn{4}{|c|}{ (a) Sexo } & \multicolumn{4}{|c|}{ (b) Escolaridade } \\
\hline & \multirow{2}{*}{$\begin{array}{c}\text { Diferença } \\
\text { no ajuste } \\
\text { da ocupação }\end{array}$} & \multicolumn{3}{|c|}{ Fatores explicativos da diferença } & \multirow{2}{*}{$\begin{array}{c}\text { Diferença } \\
\text { no ajuste } \\
\text { da ocupação }\end{array}$} & \multicolumn{3}{|c|}{ Fatores explicativos da diferença } \\
\hline & & $\begin{array}{l}\text { Nivel } \\
\text { inicial de } \\
\text { ocupação }\end{array}$ & $\begin{array}{l}\text { Distribuição } \\
\text { setorial }\end{array}$ & $\begin{array}{l}\text { Variação da } \\
\text { ocupação } \\
\text { setorial }\end{array}$ & & $\begin{array}{l}\text { Nivel } \\
\text { inicial de } \\
\text { ocupação }\end{array}$ & $\begin{array}{l}\text { Distribuição } \\
\text { setorial }\end{array}$ & $\begin{array}{l}\text { Variação da } \\
\text { ocupação } \\
\text { setorial }\end{array}$ \\
\hline $\mathrm{BR}$ & $-0,63$ & $-0,46$ & $-0,41$ & 0,24 & $-0,58$ & 0,49 & $-0,20$ & $-0,87$ \\
\hline$\%$ & {$[100,00 \%]$} & {$[73,02 \%]$} & {$[65,08 \%]$} & {$[-38,10 \%]$} & {$[100,00 \%]$} & {$[-84,48 \%]$} & {$[34,48 \%]$} & {$[150,00 \%]$} \\
\hline $\mathrm{AC}$ & $-2,29$ & $-0,80$ & 0,93 & $-2,42$ & $-1,62$ & 0,78 & 1,23 & $-3,62$ \\
\hline AP & $-4,79$ & $-1,86$ & 0,26 & $-3,18$ & $-3,06$ & 1,46 & $-0,77$ & $-3,75$ \\
\hline $\mathrm{AM}$ & $-0,39$ & $-0,64$ & $-0,97$ & 1,22 & $-1,26$ & 0,74 & $-0,07$ & $-1,92$ \\
\hline $\mathrm{PA}$ & $-0,62$ & $-0,61$ & $-1,00$ & 0,99 & 0,49 & 0,52 & $-2,01$ & 1,98 \\
\hline $\mathrm{RO}$ & $-2,84$ & $-0,34$ & 0,23 & $-2,73$ & 0,34 & $-0,09$ & 1,16 & $-0,72$ \\
\hline $\mathrm{RR}$ & $-2,31$ & $-1,41$ & $-1,34$ & 0,44 & $-2,34$ & 1,81 & $-2,67$ & $-1,49$ \\
\hline TO & $-2,01$ & $-0,96$ & $-0,99$ & $-0,06$ & $-2,80$ & 0,90 & $-0,36$ & $-3,33$ \\
\hline $\mathrm{AL}$ & $-0,42$ & $-1,54$ & $-1,41$ & 2,53 & $-0,67$ & 1,50 & $-3,80$ & 1,63 \\
\hline $\mathrm{BA}$ & 0,34 & $-0,76$ & 0,01 & 1,09 & $-0,91$ & 1,25 & $-0,08$ & $-2,09$ \\
\hline $\mathrm{CE}$ & $-0,68$ & $-0,43$ & $-0,47$ & 0,22 & $-1,54$ & 0,53 & $-0,48$ & $-1,60$ \\
\hline MA & $-2,62$ & $-1,73$ & $-0,86$ & $-0,03$ & $-1,89$ & 1,69 & $-1,15$ & $-2,43$ \\
\hline PB & $-0,57$ & $-0,57$ & 0,94 & $-0,94$ & $-0,22$ & 0,71 & 2,05 & $-2,99$ \\
\hline $\mathrm{PE}$ & $-1,31$ & $-0,97$ & $-0,63$ & 0,29 & $-2,59$ & 1,21 & $-0,42$ & $-3,38$ \\
\hline PI & $-1,44$ & $-1,48$ & 0,22 & $-0,18$ & $-2,34$ & 1,54 & $-0,34$ & $-3,55$ \\
\hline $\mathrm{RN}$ & $-0,03$ & $-0,53$ & 0,85 & $-0,36$ & $-0,79$ & 0,74 & 1,30 & $-2,83$ \\
\hline $\mathrm{SE}$ & $-1,67$ & $-0,97$ & 0,08 & $-0,78$ & 1,21 & 0,68 & $-0,45$ & 0,99 \\
\hline $\mathrm{DF}$ & 0,03 & $-0,19$ & 0,78 & $-0,56$ & 1,93 & 0,23 & 1,07 & 0,62 \\
\hline GO & $-0,50$ & $-0,33$ & $-0,28$ & 0,11 & $-1,79$ & 0,35 & $-0,03$ & $-2,11$ \\
\hline MT & 0,49 & $-0,63$ & $-1,09$ & 2,21 & 0,48 & 0,60 & $-0,07$ & $-0,05$ \\
\hline MS & $-0,62$ & $-0,36$ & $-0,92$ & 0,66 & $-1,25$ & 0,32 & $-0,79$ & $-0,78$ \\
\hline ES & $-0,01$ & $-0,15$ & $-0,15$ & 0,29 & 0,36 & 0,26 & 0,20 & $-0,10$ \\
\hline MG & $-0,04$ & $-0,12$ & $-0,23$ & 0,30 & $-0,73$ & 0,18 & 0,05 & $-0,96$ \\
\hline $\mathrm{RJ}$ & $-1,85$ & $-0,61$ & $-0,45$ & $-0,80$ & $-0,32$ & 0,44 & $-0,22$ & 0,53 \\
\hline SP & $-0,37$ & $-0,17$ & $-0,89$ & 0,69 & $-0,11$ & 0,20 & $-0,49$ & 0,18 \\
\hline PR & $-0,22$ & $-0,36$ & 0,03 & 0,11 & 0,05 & 0,39 & 0,48 & $-0,82$ \\
\hline RS & $-0,54$ & $-0,19$ & 0,27 & $-0,62$ & 0,19 & 0,15 & 0,92 & $-0,88$ \\
\hline $\mathrm{SC}$ & 0,14 & 0,09 & $-0,01$ & 0,06 & 0,66 & $-0,06$ & 0,47 & 0,26 \\
\hline
\end{tabular}

Fonte: Elaboração dos autores, a partir da PNADC/IBGE. 
Embora haja certas particularidades, pode-se destacar que, nas UFs do Norte e Nordeste, os homens tiveram os piores ajustes da ocupação, como pode ser verificado pela maior magnitude (negativa) das diferenças de sexo, em comparação aos valores nas demais regiões. Os determinantes disso são, em geral, a maior queda na ocupação setorial dos homens (Acre, Amapá) ou o nível de ocupação inicial masculino muito superior ao das mulheres (Maranhão e Piauí).

Na parte (b) da Tabela 2, são apresentados os resultados para as diferenças de escolaridade no ajuste ocupacional. Nesse caso, a base de comparação são os trabalhadores menos escolarizados, em relação aos mais escolarizados. Anteriormente, constatou-se que os menos escolarizados denotaram as maiores reduções ocupacionais. Assim, o valor de $-0,58$ revela que o nível de ocupação dos indivíduos pouco qualificados caiu 0,58 p.p. a mais do que o dos mais qualificados no período.

A principal parcela dessa diferença alude à diferença nas variações da ocupação setorial entre os dois grupos (-0,87). Esse fator correspondeu a $150 \%$ da diferença total, sugerindo que os três setores reduziram em maior intensidade o emprego para os trabalhadores menos escolarizados. A distribuição dos trabalhadores de menor escolaridade nos setores mais impactados pela recessão, em especial na indústria, explicou $34,48 \%$ da diferença total $(-0,20)$. Finalmente, os níveis iniciais de ocupação dos trabalhadores mais escolarizados, ao serem maiores, afetaram negativamente essa última categoria e contribuíram para atenuar a diferença total $(0,49)$.

Em algumas UFs, como no Paraná, no Rio Grande do Sul e em Santa Catarina, os trabalhadores menos qualificados foram, relativamente, menos penalizados, como pode ser visto pelo sinal positivo da diferença no ajuste ocupacional, e isso se deve, sobretudo, aos efeitos da distribuição setorial. Possivelmente, os trabalhadores menos escolarizados, cuja representatividade na agricultura é maior, beneficiaram-se da elevação no emprego agrícola ocorrida nessas UFs.

A parte (a) da Tabela 3 apresenta os resultados para as diferenças de idade no ajuste da ocupação, tendo como base de comparação os jovens, em relação aos adultos. A diferença de 0,49 sugere que os jovens tiveram uma redução, moderadamente, menor no emprego, por isso o valor é positivo. O resultado indica que o nível de ocupação média dos adultos caiu 0,49 p.p. a mais do que o dos jovens. O resultado é atribuído, principalmente, aos níveis iniciais de ocupação mais elevados dos trabalhadores adultos $(0,71)$, o que correspondeu à $144,90 \%$ da diferença de ajuste. Os jovens registraram as maiores reduções percentuais na ocupação setorial, por isso, essa parcela é negativa para estes trabalhadores $(-0,18)$, equivalendo a $-36,73 \%$ da diferença de ajuste ocupacional.

A distribuição setorial, cujo valor é de -0,04, apesar de penalizar os mais jovens, exerceu pouco efeito na diferença total $(-8,16 \%)$. O declínio na ocupação juvenil foi maior no Pará, no Ceará, na Paraíba, no Piauí e no Distrito Federal. Nesses locais, a queda na ocupação setorial dos jovens foi bem mais expressiva do que o verificado 
nas demais UFs brasileiras, contribuindo para esse resultado.

Tabela 3. Decomposição das diferenças no ajuste da ocupação por idade e cor, Brasil e unidades federativas, 2012-2017

\begin{tabular}{|c|c|c|c|c|c|c|c|c|}
\hline \multirow{3}{*}{ UF } & \multicolumn{4}{|c|}{ (a) Idade } & \multicolumn{4}{|c|}{ (b) Cor } \\
\hline & \multirow{2}{*}{$\begin{array}{c}\text { Diferença } \\
\text { no ajuste } \\
\text { da ocupação }\end{array}$} & \multicolumn{3}{|c|}{ Fatores explicativos da diferença } & \multirow{2}{*}{$\begin{array}{c}\text { Diferença } \\
\text { no ajuste } \\
\text { da ocupação }\end{array}$} & \multicolumn{3}{|c|}{ Fatores explicativos da diferença } \\
\hline & & $\begin{array}{l}\text { Nível } \\
\text { inicial de } \\
\text { ocupação }\end{array}$ & $\begin{array}{l}\text { Distribuição } \\
\text { setorial }\end{array}$ & $\begin{array}{l}\text { Variação da } \\
\text { ocupação } \\
\text { setorial }\end{array}$ & & $\begin{array}{l}\text { Nivel } \\
\text { inicial de } \\
\text { ocupação }\end{array}$ & $\begin{array}{l}\text { Distribuição } \\
\text { setorial }\end{array}$ & $\begin{array}{l}\text { Variação da } \\
\text { ocupação } \\
\text { setorial }\end{array}$ \\
\hline $\mathrm{BR}$ & 0,49 & 0,71 & $-0,04$ & $-0,18$ & 1,09 & $-0,04$ & $-0,16$ & 1,29 \\
\hline$\%$ & {$[100,00 \%]$} & [144,90\%] & {$[-8,16 \%]$} & {$[-36,73 \%]$} & {$[100,00 \%]$} & {$[-3,67 \%]$} & {$[-14,68 \%]$} & {$[118,35 \%]$} \\
\hline $\mathrm{AC}$ & 1,15 & 0,74 & 0,10 & 0,32 & $-0,12$ & $-0,06$ & $-0,87$ & 0,81 \\
\hline AP & 0,13 & 3,59 & 0,00 & $-3,46$ & 2,29 & 0,03 & 1,50 & 0,75 \\
\hline $\mathrm{AM}$ & 1,80 & 0,69 & 0,76 & 0,35 & 1,61 & 0,00 & $-4,47$ & 6,07 \\
\hline $\mathrm{PA}$ & $-0,82$ & 1,67 & $-0,13$ & $-2,36$ & $-0,06$ & $-0,04$ & $-0,10$ & 0,08 \\
\hline $\mathrm{RO}$ & 0,88 & $-0,47$ & $-0,02$ & 1,37 & $-0,16$ & 0,01 & 0,15 & $-0,33$ \\
\hline $\mathrm{RR}$ & 2,12 & 2,40 & 0,46 & $-0,74$ & $-1,01$ & $-0,34$ & 0,88 & $-1,54$ \\
\hline TO & 1,06 & 1,24 & $-0,26$ & 0,09 & 0,78 & $-0,05$ & $-0,16$ & 0,99 \\
\hline $\mathrm{AL}$ & 0,25 & 3,33 & $-0,48$ & $-2,60$ & 1,00 & $-0,24$ & 0,49 & 0,75 \\
\hline $\mathrm{BA}$ & 0,41 & 1,91 & 0,01 & $-1,52$ & $-0,03$ & $-0,11$ & 0,01 & 0,07 \\
\hline $\mathrm{CE}$ & $-0,25$ & 0,87 & $-0,31$ & $-0,81$ & 1,86 & 0,03 & 0,22 & 1,62 \\
\hline MA & 2,12 & 1,65 & $-0,03$ & 0,50 & 0,98 & $-0,07$ & $-0,10$ & 1,15 \\
\hline PB & $-0,69$ & 1,66 & $-0,18$ & $-2,18$ & 1,03 & $-0,03$ & $-0,22$ & 1,28 \\
\hline $\mathrm{PE}$ & 1,37 & 1,09 & $-0,03$ & 0,31 & 2,21 & $-0,01$ & 0,03 & 2,21 \\
\hline PI & $-1,44$ & 3,61 & 0,07 & $-5,11$ & 2,78 & $-0,04$ & 0,33 & 2,48 \\
\hline $\mathrm{RN}$ & 0,72 & 1,03 & $-0,12$ & $-0,19$ & 2,23 & 0,00 & $-0,24$ & 2,47 \\
\hline $\mathrm{SE}$ & 1,37 & 0,89 & $-0,18$ & 0,65 & $-0,17$ & $-0,10$ & 0,10 & $-0,17$ \\
\hline $\mathrm{DF}$ & $-1,09$ & 2,01 & 0,03 & $-3,13$ & $-0,91$ & $-0,04$ & $-0,18$ & $-0,70$ \\
\hline GO & 0,31 & 0,55 & $-0,32$ & 0,08 & 0,56 & $-0,01$ & 0,29 & 0,27 \\
\hline MT & 0,43 & 1,08 & 0,00 & $-0,65$ & 0,08 & $-0,11$ & 0,23 & $-0,04$ \\
\hline MS & 0,74 & 0,37 & $-0,05$ & 0,42 & 0,63 & $-0,01$ & 0,02 & 0,62 \\
\hline ES & 0,85 & 0,56 & 0,02 & 0,27 & $-0,12$ & $-0,06$ & $-0,10$ & 0,04 \\
\hline MG & 0,31 & 0,22 & $-0,07$ & 0,16 & 1,07 & 0,01 & 0,05 & 1,01 \\
\hline $\mathrm{RJ}$ & 1,13 & 0,32 & 0,07 & 0,73 & 0,35 & $-0,03$ & 0,17 & 0,22 \\
\hline SP & 0,73 & 0,25 & $-0,06$ & 0,54 & 0,89 & $-0,01$ & 0,13 & 0,77 \\
\hline $\mathrm{PR}$ & 1,03 & 0,32 & $-0,15$ & 0,86 & 0,68 & $-0,05$ & 0,10 & 0,63 \\
\hline RS & 0,73 & 0,17 & $-0,46$ & 1,02 & $-0,55$ & $-0,04$ & 0,11 & $-0,62$ \\
\hline $\mathrm{SC}$ & 0,63 & $-0,17$ & $-0,42$ & 1,22 & 0,60 & 0,02 & 0,12 & 0,45 \\
\hline
\end{tabular}

Fonte: Elaboração dos autores, a partir da PNADC/IBGE. 
No que diz respeito à diferença de cor, a parte (b) da Tabela 3 apresenta os resultados para as diferenças no ajuste ocupacional entre brancos e não brancos, tendo como base de comparação os brancos. A diferença entre os dois grupos $(1,09)$ se deve, essencialmente, à diferença na variação da ocupação setorial $(1,29)$, constituindo $118,35 \%$ da disparidade de cor. Portanto, o valor de 1,09 p.p. implica que a mão de obra branca obteve uma redução relativamente menor do nível de ocupação, principalmente, porque os empregos foram reduzidos em maior magnitude para os não brancos nos setores de atividade. O componente referente à diferença de distribuição setorial $(-0,16)$, por outro lado, beneficiou os não brancos e isso pode estar associado à maior representatividade desses trabalhadores no agronegócio brasileiro. Em relação à parcela pertinente ao nível inicial de ocupação, esse componente foi pouco expressivo $(-0,04)$, possivelmente porque o hiato ocupacional pré-crise entre brancos e não brancos foi o menor entre todos os grupos.

No que concerne às especificidades regionais, o Nordeste comporta as maiores diferenças percentuais de ajuste ocupacional entre os dois grupos, devido ao declínio, comparativamente, maior na ocupação setorial para os não brancos (Pernambuco, Piauí e Rio Grande do Norte). Por outro lado, no Rio Grande do Sul, no Distrito Federal e em Roraima, a redução na ocupação setorial foi maior para os brancos, levando a uma maior redução no nível de ocupação para esse grupo.

De modo geral, alguns resultados podem ser destacados. Primeiramente, os grupos de trabalhadores tradicionalmente desfavorecidos não se mostraram, necessariamente, os mais vulneráveis à crise econômica brasileira. No caso das mulheres e dos jovens, em muitos países em desenvolvimento, esses grupos foram os mais expostos às crises econômicas e, portanto, perderam relativamente mais empregos do que os homens e os trabalhadores adultos (Sabarwal e Buvinic, 2012; Signorelli e Marelli, 2012; Haouas e Guirreri, 2014). No Brasil, no entanto, tais grupos foram menos afetados. Os indivíduos menos escolarizados, por sua vez, sofreram os efeitos mais graves da crise em comparação aos mais qualificados, corroborando os achados de Furtado (2016) para o Brasil e de Glewwe (1998) e Vukšic (2014) para outros países em desenvolvimento. Quanto aos não brancos, verificou-se que esses trabalhadores apresentaram reduções mais bruscas da ocupação em contraste com os brancos, confirmando os resultados de Proni (2015).

Com relação aos fatores explicativos das diferenças de ajuste da ocupação, os altos níveis de ocupação pré-crise dos homens e dos adultos foram os principais determinantes das diferenças de sexo e idade, enquanto a diferença de variação na ocupação setorial correspondeu à maior parcela das disparidades de escolaridade e cor. A distribuição setorial também foi um aspecto importante na explicação das diferenças de sexo e escolaridade, porém, teve um papel secundário na determinação das diferenças de idade e cor.

A segregação ocupacional, a expressiva redução na ocupação setorial dos grupos vulneráveis e seus níveis inferiores de ocupação pré-crise têm como pano de fundo as 
disparidades nos atributos produtivos dos trabalhadores e a discriminação estatística (Doeringer, 1985; Phelps, 1972). Em um ambiente de informações assimétricas, os estereótipos estatísticos e a percepção das empresas quanto às características dos trabalhadores influenciam as decisões de demanda por mão de obra e afetam, sobretudo, os indivíduos mais vulneráveis (Cho, 2013). Como argumentam Glewwe (1998), alguns trabalhadores podem ter empregos menos estáveis porque são menos valiosos para as empresas. Os jovens, por exemplo, têm pouco capital humano e, portanto, possuem maior probabilidade de perderem seus empregos durante as recessões. Adicionalmente, pode ser que as mudanças tecnológicas de longo prazo estejam se movendo em favor de indivíduos altamente qualificados, fazendo com que os choques macroeconômicos produzam mudanças na demanda de trabalho nessa direção. Isso implica que trabalhadores menos qualificados são mais suscetiveis aos ciclos econômicos (Glewwe, 1998).

Também, como ficou claro, os movimentos na oferta de trabalho por parte dos grupos vulneráveis tendem a ser mais instáveis e atrelados aos movimentos da atividade econômica, o que reflete nas diferenças de variação ocupacional. A título de exemplo, Silva (2018) mostram que, desde meados de 2014, a perda de emprego dos chefes de família homens tem gerado efeitos sobre a oferta de trabalho das esposas, principalmente por meio da transição da inatividade para o desemprego.

No que diz respeito aos aspectos regionais, a extensão em que o emprego declinou e as diferenças no ajuste da ocupação dos grupos variaram notavelmente entre as UFs, sendo nítida a maior vulnerabilidade no Norte e Nordeste. Nomeadamente, nas UFs menos desenvolvidas, como em Alagoas, Maranhão, Piauí e Roraima, a redução ocupacional foi mais expressiva do que o verificado, por exemplo, em Santa Catarina, São Paulo e Minas Gerais. Esses resultados, possivelmente, estão associados ao aumento na participação dos trabalhadores e aos crescimentos no trabalho informal e no emprego agrícola nas regiões mais ricas.

Ainda, percebe-se que nas regiões mais pobres do país as diferenças nos ajustes de emprego entre os grupos destoaram da média nacional. As disparidades de sexo, por exemplo, foram ampliadas nas Regiões Norte e Nordeste, principalmente porque a superioridade dos homens nos níveis de ocupação pré-crise foi mais elevada nesses locais. Assim, a redução do emprego foi proporcionalmente maior para esses grupos em tais regiões. Quanto às características de escolaridade e cor, as diferenças no ajuste também foram mais expressivas nas UFs do Norte e Nordeste em função da redução relativamente maior na ocupação setorial para os grupos desfavorecidos.

Um último ponto diz respeito ao papel do setor informal durante o período de recessão. Em particular, as mulheres, os mais escolarizados, os adultos e os não brancos se destacaram como os grupos com as maiores taxas de crescimento no emprego informal entre 2015 e 2017. Esses resultados podem ter contribuído para o melhor desempenho dos indivíduos mais qualificados e dos adultos na parcela referente às diferenças de variação na ocupação setorial. Objetivamente, como exposto, esses dois 
grupos apresentaram resultados positivos nessa parcela da diferença total e esse resultado, supostamente, foi influenciado pelo crescimento da informalidade entre tais indivíduos.

Além disso, para alguns grupos e em algumas UFs, o maior grau de formalidade no emprego pode ter sido relevante na preservação das ocupações durante o período recessivo. Esse é o caso dos trabalhadores adultos e dos brancos e, também, de algumas UFs do Sul e Sudeste. Por outro lado, a maior informalidade entre os jovens e os não brancos e em certas UFs do Norte e Nordeste resultou em elevado contingente de trabalhadores sem acesso aos mecanismos de proteção social, deixando-os vulneráveis às adversidades da crise econômica brasileira ${ }^{11}$. Portanto, o setor informal, apesar de sua importância, permanece se caracterizando por empregos com pouca regulação trabalhista, baixos rendimentos e exígua proteção social. Como pontuam Botelho (2011), parte considerável da segmentação laboral no Brasil tem como causa a inserção de uma massa expressiva de trabalhadores na informalidade.

\section{Considerações finais}

O presente estudo verificou os efeitos imediatos da crise econômica brasileira sobre o nível de ocupação de diferentes grupos de trabalhadores para o Brasil e para as unidades federativas brasileiras e identificou os fatores explicativos das diferenças dos grupos no ajuste do nível ocupacional. Para tanto, o método aplicado foi a decomposição de Shapley, utilizando os microdados da PNADC para o período 2012-2017.

Os resultados apontaram que, para todos os grupos, a queda no nivel de ocupação ocorreu em função do declínio na taxa de ocupação. A participação no mercado de trabalho, por outro lado, aumentou no período, especialmente para as mulheres e para os jovens. A título de exemplo, o nível de ocupação dos homens caiu 1,49 p.p. entre os períodos pré-crise e de crise, dos quais 1,58 p.p. foi devido à queda na taxa de ocupação, enquanto a participação masculina no mercado de trabalho aumentou em 0,09 p.p. Além disso, os grupos de indivíduos homens, com baixa escolaridade, adultos e não brancos, sofreram as maiores reduções do nível de ocupação em relação aos trabalhadores do gênero feminino, mais escolarizados, jovens e brancos.

Quanto aos fatores que explicam as diferenças dos grupos no ajuste ocupacional, o nível de ocupação dos homens caiu 0,63 p.p. a mais do que o das mulheres no período, devido aos altos níveis de emprego pré-crise dos homens, representando $73,02 \%$ da diferença de sexo e, também, devido à maior representatividade masculina na indústria, correspondendo a $65,08 \%$ da diferença total. A parcela referente à diferença na variação da ocupação setorial correspondeu a $-38,10 \%$ da diferença total, indicando que os setores da indústria, da agricultura e dos serviços reduziram o emprego feminino em maior magnitude do que o masculino.

\footnotetext{
${ }^{11} \mathrm{Em}$ 2017, a proporção de trabalhadores em ocupações informais alcançou 59,5\% na Região Norte e $56,2 \%$ na Região Nordeste. Já as Regiões Sudeste e Sul apresentaram proporções de, respectivamente, 33,8\% e 29,1\% (Instituto Brasileiro de Geografia e Estatística - IBGE, 2018).
} 
Com relação às disparidades educacionais no ajuste da ocupação, os indivíduos menos escolarizados denotaram as maiores reduções na ocupação devido à queda mais expressiva na ocupação setorial para esses indivíduos e, também, por sua maior representatividade nos setores mais negativamente afetados pelo choque recessivo, como a indústria.

Os trabalhadores adultos, por sua vez, sofreram maiores reduções ocupacionais, em comparação aos jovens, devido, sobretudo, aos níveis iniciais de ocupação superiores dos adultos. Por fim, os indivíduos não brancos retrataram reduções mais pronunciadas no nível de ocupação do que os brancos, pois a ocupação setorial caiu em maior magnitude para essa última categoria. A parcela referente à distribuição setorial, por outro lado, beneficiou os não brancos, possivelmente, por serem mais representativos na agricultura.

Quanto aos aspectos regionais, a amplitude em que a ocupação declinou e as diferenças no ajuste ocupacional entre os grupos variaram substancialmente entre as regiões brasileiras. Particularmente, nas UFs mais desenvolvidas economicamente, a redução na ocupação foi menor, o que esteve associado ao aumento na participação dos trabalhadores no mercado de trabalho, às elevações na informalidade e no emprego agrícola e ao maior grau de formalidade nessas localidades.

Por fim, ressalta-se que o método de decomposição aplicado no estudo teve por objetivo analisar, notadamente, as mudanças relativas ao emprego no período de crise econômica, evidenciando regionalmente essa reorganização no mercado de trabalho. Isto posto, uma prioridade para pesquisas futuras é abordar outras importantes dimensões do mercado de trabalho brasileiro, como os salários, os rendimentos e as horas trabalhadas.

Sendo assim, os resultados encontrados sugerem que os grupos de indivíduos tradicionalmente desfavorecidos podem não ser os mais vulneráveis aos choques recessivos. Nesse contexto, infere-se que as políticas públicas que visam mitigar os impactos adversos da recessão, além de priorizarem os grupos desfavorecidos, devem estar atentas aos setores e às regiões mais penalizados, estimulando a criação de empregos e promovendo o desenvolvimento econômico.

\section{Referências}

Arrow, K. (1971). The theory of discrimination. Conference on Discrimination on labor markets: Princeton University. (Working Paper, n. 30A).

Barakat, B. (2010). The Impact of the Economic Crisis on Labour and Education in Europe. Vienna Institute of Demography. Vienna Institute of Demography. (Working Paper, n. 6).

Barbosa Filho, F. H. (2017). A crise econômica de 2014/2017. Estudos Avançados, 31(89):30-45. 
Bluestone, B. (1968). Low wage industries and the working poor. Powerty and Human Resources Abstracts, 3(2):1-14.

Botelho, F.; Ponczek, V. (2011). Segmentation in the Brazilian labor market. Economic Development and Cultural Change, 59(2):437-463.

Bredemeier, C.; Winkler, R. (2017). The employment dynamics of different population groups over the business cycle. Applied Economics, 49(26):2545-2562.

Cacciamali, M. C.; Tatei, F. (2016). Mercado de trabalho: da euforia do ciclo expansivo e de inclusão social à frustração da recessão econômica. Estudos Avançados, 30(87):103-121.

Cardoso, A. L.; Aragão, T. A. e Jaenisch, S. T. (2017). Vinte e dois anos de política habitacional no Brasil: da euforia à crise. In: Cardoso, A. L.; Aragão, T. A. e Jaenisch, S. T., editores, Vinte e dois anos de política habitacional no Brasil: da euforia à crise, Página 15-48. Letra Capital, 1 edition.

Cho, Y.; Newhouse, D. (2013). How did the great recession affect different types of workers? Evidence from 17 middle-income countries. World Development, 41(1):3150.

Choudhry, M. T.; Marelli, E. e Signorelli, M. (2012). Youth unemployment rate and impact of financial crises. International Journal of Manpower, 33(1):76-95.

Doeringer, P.; Piore, M. (1985). Internal labor markets and manpower analysis. Lexington, Mass: Heat.

Elsby, M. W.; Hobijn, B. e Sahin, A. (2010). The labor market in the Great Recession. National Bureau of Economic Research. (Working Paper, 15979).

Fallon, P. R.; Lucas, R. E. B. (2002). The impact of financial crises on labor markets, household incomes, and poverty: A review of evidence. The World Bank Research Observer.

Flori, P. M. (2005). Desemprego de jovens no Brasil. Revista da Associação Brasileira de Estudos do Trabalho, 5(1):127-143.

Furtado, A. (2016). Desemprego entre jovens: situação do Brasil e lições da experiência internacional. Estudo Técnico, Câmara dos Deputados, Brasília. Disponível em: http://www2.camara.leg.br/documentos-epesquisa/publicacoes/estnottec/areas-daconle/tema7/2016_12418_desempregoentre-jovens_adolfo-furtado. Acesso em: 24 abr. 2018.

Glewwe, P.; Hall, G. (1998). Are some groups more vulnerable to macroeconomic shocks than others? Hypothesis tests based on panel data from Peru. Journal of development economics, 56(1):23-47. 
Gonzaga, G.; Reis, M. C. (2011). Oferta de trabalho e ciclo econômico: os efeitos trabalhador adicional e desalento no Brasil. Revista Brasileira de Economia, 65(2):127148.

Gutierrez, C. (2007). Does employment generation really matter for poverty reduction? The World Bank. (Working Paper, n. 4432).

Haouas, I.; Yagoubi, M. e Guirreri, S. (2014). The Effect of Financial Crisis on Hiring and Separation Rates: Evidence from Tunisian Labor Market. The Journal of Developing, 48(3):56-78.

Hoynes, H.; Miller, D. L. e Schaller, J. (2012). Who suffers during recessions? Journal of Economic perspectives, 26(3):27-48.

Instituto Brasileiro de Geografia e Estatística - IBGE (2018). Síntese de Indicadores Sociais. Uma análise das condições de vida da população brasileira. Disponível em:https://biblioteca.ibge.gov.br/visualizacao/livros/liv101459.pdf. Acesso em: 28 dez. 2019.

Neri, M. C. (2002). Decent Work and the Informal Sector in Brazil. Ensaios Econômicos.

Nunes, D. U.; Menezes Filho, N. A. e Komatsu, B. K. (2016). Probabilidades de admissão e desligamento no mercado de trabalho brasileiro. Estudos Econômicos, 46(2):311-341.

Oliveira, E. L.; Rios Neto, E. G. e Oliveira, A. M. H. C. (2014). O efeito trabalhador adicional para filhos no Brasil. Revista Brasileira de Estudos de População, 31(1).

Parker, S. W.; Skoufias, E. (2004). The added worker effect over the business cycle: evidence from urban Mexico. Applied Economics Letters, 11(10):625-630.

Phelps, E. S. (1972). The statistical theory of racism and sexism. The American Economic Review, 62(4):659-661.

Pochmann, M. (2015). Ajuste econômico e desemprego recente no Brasil metropolitano. Estudos Avançados, 29(85):7-19.

Pochmann, M. (2018). Desempenho econômico conjuntural e a situação recente do trabalho no Brasil. Revista do Núcleo de Estudos de Economia Catarinense, 7(13): 1228.

Proni, M. W.; Gomes, D. C. (2015). Precariedade ocupacional: uma questão de gênero e raça. Estudos Avançados, 29(85):137-151.

Quintini, G.; Martin, J. P. e Martin, S. (2007). The changing nature of the school to work transition process in OECD countries. Institute for the Study of Labor. (Discussion Papers, n. 2582). 
Reich, M.; Gordon, D. M. e Edwards, R. C. A. (1973). Theory of labor market segmentation. The American Economic Review, 63(2):359-365.

Rezende, G. C. (1989). Agricultura e ajuste externo no Brasil: novas considerações. Pesquisa e Planejamento Econômico, 19(3):35-45.

Sabarwal, S.; Sinha, N. e Buvinic, M. (2012). How do women weather economic shocks? What we know. Economic Premise. (Working Paper, n. 46).

Shorrocks, A. (2013). Decomposition procedures for distributional analysis: A unified framework based on the Shapley value. The Journal of Economic Inequality, 11(1):99126.

Signorelli, M.; Choudhry, M. e Marelli, E. (2012). The Impact of Financial Crises on Female Labour. European Journal of Development Research, 24:413-433.

Silva, P. L. N.; Pessoa, D. G. C. e Lila, M. F. (2002). Análise estatística de dados da PNAD: incorporando a estrutura do plano amostral. Ciência \& Saúde Coletiva, 7(4):659-670.

Silva, C.; Cunha, M. S. (2018). O efeito do trabalhador adicional no brasil: Resposta do cônjuge ao desemprego do chefe da família (2012 a 2017). In: 46ํㅡㄹ Encontro Nacional de Economia - ANPEC, Rio de Janeiro.

Smith, J. P. e. a. (2002). Wages, employment and economic shocks: Evidence from Indonesia. Journal of Population Economics, 15(1):161-193.

Souen, J. A.; Campos, G. C. (2017). Da Euforia ao Retrocesso: O Comportamento do Emprego Formal no Brasil no Período Recente. Revista da Associação Brasileira de Estudos do Trabalho, 15(2):67-89.

Taubman, P. e Wachter, M. L. (1986). Segmented labor market. In: Ashenfelter, O. e Layard, R., editores, Handbook of Labor Economics, volume 1, Página 1183-1217. NorthHoland.

Verick, S. (2009). Who is hit hardest dis? The vulnerability of young men and women to unemployment in an economic downturn. Institute of Labor Economics. (Discussion Papers, n. 4359).

Vietorisz, T.; Harrison, B. (1973). Labor market segmentation: positive feedback and divergent development. The American Economic Review, 63(2):366-376.

Vukšic, G. (2014). Employment conditions in the current economic crisis in Croatia. Financial Theory and Practice, 38(2):103-138.

Este artigo está licenciado com uma CC BY 4.0 license. 